\title{
Bone Decalcification for Histological Examination of Biopsy Specimen
}

\section{Nurul Inaas Mahamad Apandi ${ }^{1}$, Nor Hasilah Mokhtar ${ }^{1}$, Anitha Krishnan Pandarathodiyil ${ }^{2}$ and Anand Ramanathan ${ }^{1,3 *}$}

${ }^{1}$ Department of Oral and Maxillofacial Clinical Sciences, Faculty of Dentistry, University of Malaya, Kuala Lumpur, Malaysia

${ }^{2}$ Faculty of Dentistry, SEGi University, Jalan Teknologi, Taman Sains Selangor, Kota Damansara, Petaling Jaya, Selangor, Malaysia

${ }^{3}$ Oral Cancer Research and Coordinating Centre, Faculty of Dentistry, University of Malaya, Kuala Lumpur, Malaysia

*Corresponding Author: Anand Ramanathan, Department of Oral and Maxillofacial Clinical Sciences, Faculty of Dentistry, University of Malaya, Kuala Lumpur, Malaysia.
Received: April 14, 2021

Published: April 30, 2021

(C) All rights are reserved by Anand

Ramanathan., et al.

\begin{abstract}
The process of bone decalcification involves removal of calcium salt and minerals from bone tissue completely, following adequate fixation. Within a diagnostic center, it is a gold standard procedure used for histopathological examination of biopsied specimens especially for those containing hard tissue. This technical note serves to provide an overview and brief description of the techniques used in the process of decalcification.
\end{abstract}

Keywords: Bone; Decalcification; Biopsy Specimen; Technical Note

\section{Introduction}

Biopsy is a procedure that involves the removal of tissue from a living person. The biopsied tissue is then processed for histopathological examination in order to confirm or establish a diagnosis [1]. Biopsy can be either incisional, which is removal of a part of the lesion or excisional whereby the whole specimen is removed. Specimens can include soft tissue and also hard tissue; thus, decalcification is needed especially for the hard tissue to be processed into slides to be examined under the microscope. This is in order to ease the process of cutting the specimen as without it, sectioning bone tissues becomes exceedingly difficult and unfeasible, unless they are embedded in paraffin wax and cut with powerful microtomes. The sequence of events to produce a stained bone/hard tissue section is described in figure 1 .
Sequence:

1. Hard tissue cutting (EXACT)

2. Decalcification

3. Embedding

4. Sectioning

5. Fishing

6. Staining

7. Mounting

Figure 1: Shows the sequence of procedure a stained bone/hard tissue section.

Decalcification is commonly done by using chelating agents or acid-decalcifying solutions [2]. Acids are preferred as they can 
combine with the bone calcium and form calcium salts that are soluble. Chelating agents, on the other hand, have the drawbacks of changing the staining properties of the bone [3]. However, if used in combination they have shown to produce decalcification at a faster rate and with minimal damage to the tissues. Decalcification solutions commonly used are formic acid (5-10\% in saline) [3] and ethylenediamine tetraacetate acid (EDTA) [3]. EDTA more widely used in research setting as they need longer time of action while in a diagnostic setting acid is commonly used. In the Oral Pathology and Diagnostic Research Laboratory of Dental Faculty of University Malaya, Hydrochloric acid (RDO) is used [4,5].

\section{Techniques}

Specimens can be EXACT prior to decalcification or to decalcify prior to cutting before embedding in wax. This depends on the type and size of specimen received. For incisional biopsy specimens, the hard tissue or bone is usually small sized thus will only need a few hours to be immersed in the acid solution. Whilst for excisional biopsy specimens take a longer time for up to 2 - 3 days in the acid solution to decalcify. Thus, the acid solution will be replaced daily until the desired effect is achieved. Detailed procedure is explained in figure 2 and 3 shows the specimen immersed in acid.

Decalcification procedure:

1. Specimens need to be decalcified by immersing them in hydrochloric acid or formic acid and the working solution should be 20 times their volume.

2. Fresh solutions need to be used on a daily basis until decalcification is complete. Complete decalcification may take hours, days or months based on their size. Below is a description of the testing procedures.

3. Upon complete decalcification, the specimen needs to be rinsed in water for a brief period of time and immersed in ammonia solution for about half an hour. This step would neutralize the acids present in the specimen.

4. Following the immersion in ammonia solution for $30 \mathrm{~min}-$ utes, the specimen needs to be rinsed under running tap water for about a day.

5. Embed the specimen in paraffin wax.

Figure 2: Describes the detailed decalcification procedure.

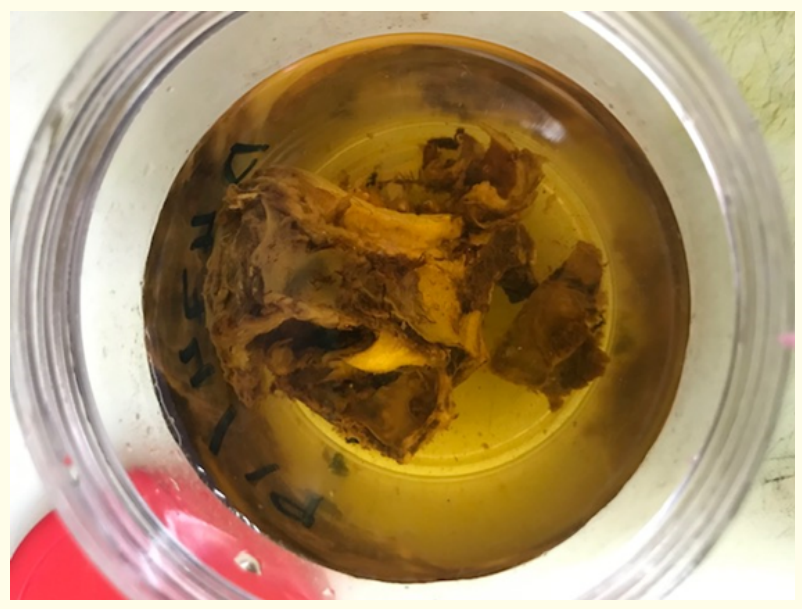

Figure 3: Photograph shows the specimen immersed in hydrochloric acid.

After decalcification, the specimens are embedded in wax and trimmed using the microtome to yield 4 - $5 \mu$ thick sections. Then, they are fished and secured on a glass slide and dewaxed. Following which, the section is ready for staining with hematoxylin and eosin (H\&E) to highlight the tissue features and enabling diagnosis to be rendered (Figure 4-6).

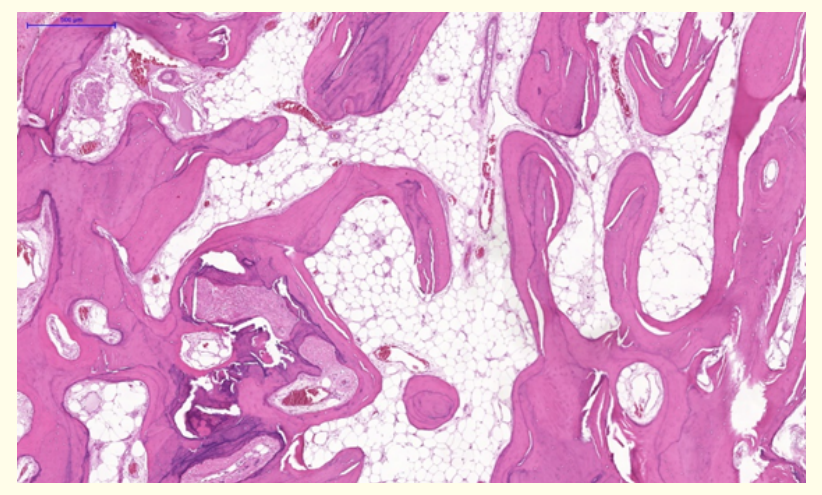

Figure 4: Photomicrograph shows trabeculae of vital bone cortex and fibrovascular marrow (Original magnification: 40x; Stain: $\mathrm{H} \& \mathrm{E})$. 


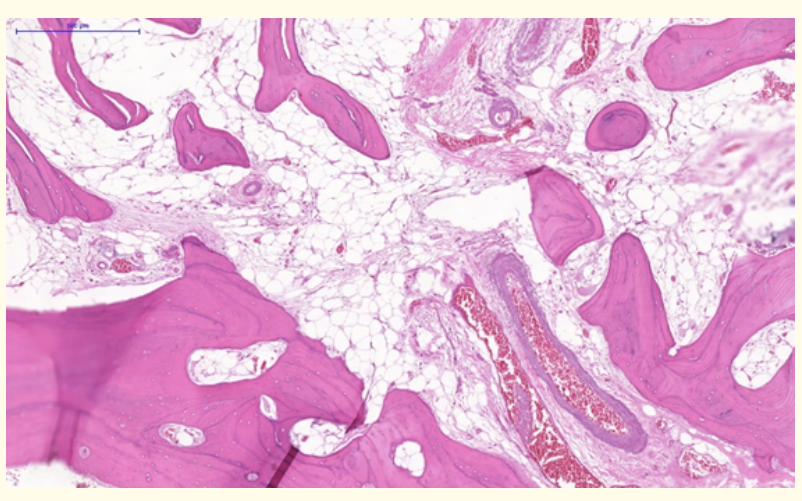

Figure 5: Photomicrograph shows fibrofatty marrow with vascular channels (Original magnification: 40x; Stain: H\&E).

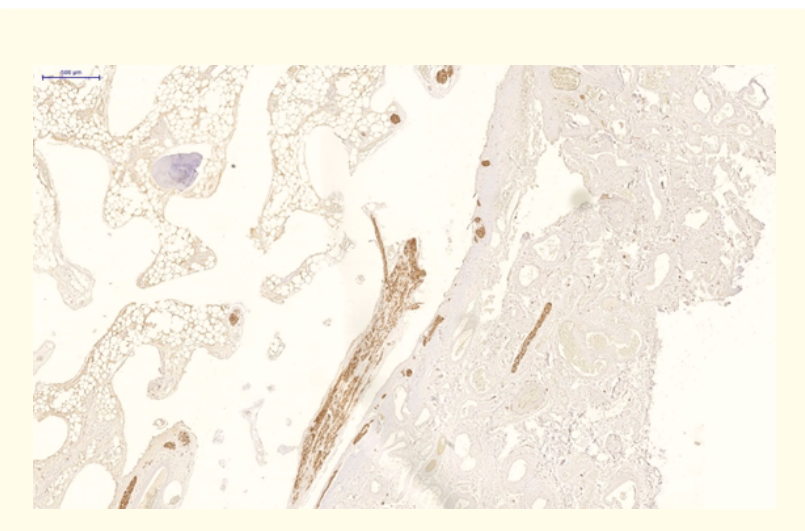

Figure 6: Photomicrograph shows anti-S100 antibody immunostaining highlighting the nerve bundles (Original magnification 40x).

Excessive decalcification could cause irreversible specimen damage. Thus, the following procedures can help determine the correct endpoint of decalcification:

1. Radiograph

2. Chemical testing

3. Physical testing.

Radiography is the most accurate method followed by chemical and physical testing procedures which are potentially damaging to the specimens. Chemical testing can be done by using equally mixed solution of $5 \%$ ammonium hydroxide stock and 5\% ammonium oxalate stock. The detailed procedure is tabled in figure 7.

\section{Chemical testing procedure:}

1. A pipette is inserted into the decalcifying solution which contains the specimen.

2. Approximately $5 \mathrm{ml}$ of the hydrochloric acid/formic acid decalcification solution is pipetted out from under the specimen and placed in a test tube.

3. Approximately $10 \mathrm{ml}$ of ammonium hydroxide/ammonium oxalate working solution is added, mixed well and left overnight.

4. Absence of any precipitate in the solution up to two successive days is indicative of complete decalcification. However, this test should be repeated every two or three days.

Figure 7: Describes the chemical testing procedure to determine the endpoint of decalcification.

There are physical tests to determine the cut-off point of complete decalcification. They include insertion of a needle or scalpel into the specimen and/or testing the flexibility of the specimen by bending it. However, there are disadvantage of these physical tests. For apparent reasons, tears and pinhole artifacts can be expected with insertion of pins and scalpels. Although bending the specimen with mild force is a safer and less damaging technique, it is not conclusive of complete decalcification. Once the specimen is tested for rigidity, it is rinsed thoroughly and then processed. In case of paraffin embedded bone specimens that are inadequately decalcified, they can be soaked in the decalcification solution for a brief period (few minutes) before cutting. This is called surface decalcification.

\section{Conclusion}

From the above explained procedure, it can be concluded that decalcification is an important procedure that contributes to histopathological diagnosis of a given hard tissue specimen. Therefore, proper and appropriate measures should be taken, to ease the examination of processed slides, by the pathologist.

\section{Conflict-of-interest:}

The authors do not have any conflict of interest.

\section{Bibliography}

1. Brain EB. "The Preparation of Decalcified Sections". Charles C. Thomas, Springfield, IL (1966). 
2. Drury RAB and Wallington EA. “Carleton's Histological Techniques”. Oxford University Press, Oxford, UK (1980): 199-220.

3. Oliver RJ., et al. "Oral biopsies: methods and applications". British Dental Journal 196.6 (2004): 329-333.

4. Verdenius HHW and Alma L. "A quantitative study of decalcification methods in histology". Journal of Clinical Pathology 11.3 (1958): 229-236.

5. Kiernan HA. "Histological and Histochemical Methods: Theory and Practice". Pergamon Press, Oxford, UK (1990): 32-35.

\section{Assets from publication with us}

- Prompt Acknowledgement after receiving the article

- Thorough Double blinded peer review

- Rapid Publication

- Issue of Publication Certificate

- High visibility of your Published work

Website: www.actascientific.com/

Submit Article: www.actascientific.com/submission.php

Email us: editor@actascientific.com

Contact us: +919182824667 